\title{
High-Surface-Area Mesoporous Activated Carbon from Hemp Bast Fiber Using Hydrothermal Processing
}

\author{
Md Zakir Hossain (D), Wei Wu, William Z. Xu, Muhammad B. I. Chowdhury, Anil Kumar Jhawar, \\ Devin Machin and Paul A. Charpentier* \\ Department of Chemical and Biochemical Engineering, The University of Western Ontario, \\ London, ON N6A 5B9, Canada; mhossa32@uwo.ca (M.Z.H.); wwu222@uwo.ca (W.W.); zxu27@uwo.ca (W.Z.X.); \\ mchowdh4@uwo.ca (M.B.I.C.); ajhawar2@uwo.ca (A.K.J.); dmachin@uwo.ca (D.M.) \\ * Correspondence: pcharpentier@eng.uwo.ca; Tel.: +1-(519)-661-3466
}

Received: 27 April 2018; Accepted: 15 June 2018; Published: 25 June 2018

\begin{abstract}
Synthesis of activated carbon from waste biomass is of current interest towards sustainability. The properties of biomass-derived activated carbon largely depend on the carbonization process. This study reports the preparation of mesoporous activated carbon with extremely high surface area from hemp bast fiber using hydrothermal processing. Hot water processing $\left(390-500{ }^{\circ} \mathrm{C}\right.$ ) followed by activation using $\mathrm{KOH}$ and $\mathrm{NaOH}$ was investigated at different mass ratios. The described approach was found to enhance the mesoporosity (centered at 3.0 to $4.5 \mathrm{~nm}$ ) of the hemp-derived activated carbon (HAC) from activation [confirmed by BJH (Barrett-Joyner-Halenda) pore size distribution and TEM (transmission electron microscopy) imaging]. BET (Brunauer-Emmett-Teller) results showed that the product has an extremely high surface area (2425 $\mathrm{m}^{2} / \mathrm{g}$ ) while the surface functional groups $(-\mathrm{OH},-\mathrm{COOH}, \mathrm{C}=\mathrm{C} / \mathrm{C}-\mathrm{C}$ ) were confirmed by FTIR (Fourier transform infrared spectroscopy) and further quantified by XPS (X-ray photoelectron spectroscopy). Increasing $\mathrm{KOH}$ concentration was found to enhance the surface area with a maximum biochar-to- $\mathrm{KOH}(\mathrm{g} / \mathrm{g}$ ) ratio of 1:3. The crystallite domain size of HAC was determined using Raman spectroscopy of different wavelengths. The procedure described in this study is an environmentally friendly scalable route for the mass production of activated carbon using hemp fiber.
\end{abstract}

Keywords: hemp bast fiber; hydrothermal processing; $\mathrm{KOH}$ activation; activated carbon

\section{Introduction}

Activated carbon is a well-known porous material with large surface area and pore volume, and is extensively used for gas separation, solvent recovery, contaminant removal from water, wastewater treatment, and as a catalyst/catalyst support for different energy storage and conversion processes [1]. Recently, activated carbon has been extensively investigated for making carbon foams [2] and ultracapacitors/supercapacitors $[3,4]$ due to its porous structure. As the pore properties of activated carbon largely depend on the precursor materials and the synthesis method, different types of materials (natural and synthetic) have been examined as precursors. The most commonly used precursors for activated carbon production are coal, coconut shell, wood, agricultural wastes, or industrial wastes [1]. Among them, biomass as a precursor is attracting significant attention as it is renewable, abundant, low cost, and eco-friendly.

Two basic activation processes, i.e., physical and chemical, are used to prepare activated carbonaceous materials from biomass [5]. Prior to either the physical or chemical activation process, the carbon precursor needs to be carbonized to produce char. If the formed char is activated using 
carbon dioxide or steam as the activating agent, the process is called physical activation [6]. If the char is activated in the presence of chemical agents, the process is termed chemical activation [7]. The step for char production can occasionally be skipped if chemical activation is employed. To obtain a well-developed pore structure in the final carbon product using physical activation, a significant amount of internal carbon mass removal is necessary. Activating agents used for chemical activation are dehydrating agents that enhance pyrolytic decomposition and prevent tar formation, thus enhancing the yield of carbon [5]. The most commonly used agents for chemical activation are acidic reagents such as $\mathrm{ZnCl}_{2}, \mathrm{H}_{3} \mathrm{PO}_{4}, \mathrm{HCl}$, and $\mathrm{H}_{2} \mathrm{SO}_{4}$ or the basic reagents $\mathrm{KOH}, \mathrm{K}_{2} \mathrm{CO}_{3}, \mathrm{NaOH}$, and $\mathrm{Na}_{2} \mathrm{CO}_{3}$. There is a growing interest in using alkali hydroxides as the activation agent, with $\mathrm{KOH}$ being one of the most promising activating agents [8,9]. In this work, $\mathrm{KOH}$ and $\mathrm{NaOH}$ are compared as activating agents while hemp bast fiber was chosen as the carbon precursor because of its unique fibrous structure to make carbonaceous materials [10]. Hemp has been used for various applications such as rod, sails, clothing, paper, building materials, food, medicine, oil, fuel, and in the plastic industry [11], with carbonized hemp fiber being studied by several research groups [11-13]. Wang et al. [11] used sulphuric acid solution in their process to prepare carbon material from hemp fiber whereas Yang et al. [12] and Rosas et al. [13] conducted the carbonization reaction in the presence of phosphoric acid. Using acid for this carbonization process provides an acid disposal issue after the reaction. Hydrothermal processing of hemp bast fiber followed by chemical activation can be an alternative approach for making carbon materials.

Detailed structural and surface properties are very important for the application of the resultant product. The current study synthesizes hemp-derived carbon materials and characterizes them in detail by various physicochemical techniques including BET (Brunauer-Emmett-Teller) surface area and BJH (Barrett-Joyner-Halenda) pore size distribution, XRD (X-ray powder diffraction), SEM (scanning electron microscopy), TEM (transmission electron microscopy), Raman, TG-DTA (thermogravimetric \& differential thermal analysis, FTIR (Fourier transform infrared spectroscopy), and XPS (X-ray photoelectron spectroscopy) analysis.

\section{Materials and Methods}

\subsection{Materials}

Hemp bast fiber was purchased from American Hemp, Winston Salem, NC, USA. KOH, $\mathrm{NaOH}$, and $36 \%$ to $40 \% \mathrm{HCl}$ were obtained from Caledon Laboratories Ltd., Georgetown, ON, Canada. Silica-alumina pellets were obtained from Micromeritics Instrument Corporation, Norcross, GA, USA. Powdered activated carbon (DARCO G-60, 100-325 mesh particle size) and Basolite ${ }^{\circledR}$ C300 were obtained from Sigma Aldrich Canada Co., Oakville, ON, Canada. Activated carbon Norit Row $0.8 \mathrm{~mm}$ pellets (steam activated) were obtained from Alfa Aesar, Tewksbury, MA, USA. Deionized (DI) water $(18.2 \mathrm{M} \Omega$ ) was taken from a compact ultrapure water system (EASY pure LF, Mandel Scientific Co., Guelph, ON, Canada, model BDI-D7381).

\subsection{Preparation of Hemp-Derived Activated Carbon (HAC)}

A quantity of $200 \mathrm{~mL}$ of DI water along with $12.0 \mathrm{~g}$ of pre-cut hemp bast fiber were sealed in a $600 \mathrm{~mL}$ Hastelloy C-276 reactor (Autoclave Engineers, Erie, PA, USA), heated to the desired temperature $\left(390{ }^{\circ} \mathrm{C}, 450{ }^{\circ} \mathrm{C}\right.$, or $\left.500{ }^{\circ} \mathrm{C}\right)$, and kept for $2 \mathrm{~h}$. The resultant biochar was recovered by vacuum filtration and washed with DI water multiple times, then dried overnight at $120^{\circ} \mathrm{C}$ in a vacuum oven. The dried biochar was thoroughly mixed with a preset amount of $\mathrm{KOH}$ or $\mathrm{NaOH}$ (wt ratios of biochar to $\mathrm{KOH}$ or $\mathrm{NaOH}: 1: 1,1: 2$, and 1:3) using a mortar and pestle, then heated to $750{ }^{\circ} \mathrm{C}\left(0.5^{\circ} \mathrm{C} / \mathrm{min}\right)$ and kept at $750{ }^{\circ} \mathrm{C}$ for $1 \mathrm{~h}$ under Argon flow in a tubular furnace. The resulting product was thoroughly washed with $20 \% \mathrm{HCl}$ followed by DI water until pH 7.0 was reached. Finally, the products were dried overnight at $120^{\circ} \mathrm{C}$ in a vacuum oven. Activation of biochar using $\mathrm{KOH}$ to 
produce the final product was repeated at least three times. The yields of final products were $59 \%$, $65 \%$, and $71 \%$ when using biochar-to- $\mathrm{KOH}$ ratios of $1: 3,1: 2$, and 1:1, respectively.

\subsection{Instrumentation}

The Brunauer-Emmett-Teller (BET) surface area, pore diameter, and pore volume of hemp-derived activated carbon (HAC) and biochar were determined from nitrogen adsorption and desorption isotherm data obtained at $-196{ }^{\circ} \mathrm{C}$ in a constant-volume adsorption apparatus (Tristar II 3020, Micromeritics Instrument Corporation, Norcross, GA, USA) using $99.995 \%$ pure $\mathrm{N}_{2}$ gas obtained from Praxair (Oakville, ON, Canada). The prepared samples were degassed at $130{ }^{\circ} \mathrm{C}$ for $12 \mathrm{~h}$ to remove any moisture and other adsorbed gases from the surface. The pore size distributions were calculated using the BJH (Barrett-Joyner-Halenda) method from the desorption branch of the isotherms. The instrument calibration was examined by using the standard (silica-alumina pellets) obtained from the instrument supplier (Micromeritics Instrument Corporation, Norcross, GA, USA). Calibration was also checked by using commercial activated carbons and Basolite where their specific surface areas are known. Details about the calibration results are provided in the Supplementary Materials (Table S1).

X-ray diffraction (XRD) measurements were performed using a Bruker D2 PHASER desktop diffractometer (Madison, WI, USA) using Cu K $\alpha$ radiation (1.54 $\AA$ ). The instrument was operated at $30 \mathrm{kV}$ and $10 \mathrm{~mA}$, using a scan rate of $0.1^{\circ}$ per second in the $2 \theta$ range from $10^{\circ}$ to $70^{\circ}$. The morphology of the HAC was obtained using Scanning Electron Microscopy (SEM) (Hitachi FlexSEM, model SU 1000) (Schaumburg, IL, USA) with a secondary electron detector and Transmission Electron Microscopy (TEM) (model JEOL 2010F) (Peabody, MA, USA). The X-ray photoelectron spectroscopy (XPS) analysis was carried out with a Kratos Axis Ultra spectrometer (Kratos Analytical Ltd., Manchester, UK) using a monochromatic $\mathrm{Al} \mathrm{K} \alpha$ source $(15 \mathrm{~mA}, 14 \mathrm{kV})$. FTIR (Fourier transform infrared) analyses of the hemp-derived samples were examined using an ATR-FTIR spectroscope (Nicolet 6700 FTIR) (ThermoFisher Scientific, Waltham, MA, USA). Raman spectroscopy measurements were performed using a Kaiser Optical Systems RXNI-785 (Ann Arbor, MI, USA) with an excitation wavelength of $785 \mathrm{~nm}$. Crystallite domain sizes of the AC catalysts were measured using a Renishaw InVia Reflex Raman spectrometer (New Mills, Gloucestershire, UK) with two additional wavelength lasers $(633 \mathrm{~nm}$ and $514 \mathrm{~nm}$ ). Thermogravimetric and differential thermal analysis (TG-DTA) was conducted on a TA Q600 system (New Castle, DE, USA) with a heating rate of $10^{\circ} \mathrm{C} / \mathrm{min}$ from ambient temperature to $1000{ }^{\circ} \mathrm{C}$ in $\mathrm{N}_{2}$ with a flow rate of $50 \mathrm{~mL} / \mathrm{min}$.

\section{Results}

Textural properties are critical for optimizing the application of any porous material. Textural properties of prepared HAC using hydrothermal processing are listed in Table 1, where the average values are reported after measuring three times. It is seen that the HAC obtained very high surface area once activated by $\mathrm{KOH}$ or $\mathrm{NaOH}$. $\mathrm{KOH}$ demonstrated advantages over $\mathrm{NaOH}$ in pore development of biochar. Both the BET and Langmuir surface areas slightly increase with increasing biochar synthesis temperature from $390{ }^{\circ} \mathrm{C}$ to $500{ }^{\circ} \mathrm{C}$. Generally, the pore volume and pore size of the final product were found to be insensitive to the biochar synthesis temperature.

Table 2 compares the BET surface areas of activated carbon obtained in the present study with those obtained using different feedstocks/activating reagents reported in the literature, with the present study showing the highest BET surface area of $2425 \mathrm{~m}^{2} / \mathrm{g}$. It is generally believed that the $\mathrm{KOH}$ activation process of any carbon material enhances the pore structure and morphology with a substantial increase in specific surface area [14]. 
Table 1. Pore properties of hemp-derived activated carbon (HAC).

\begin{tabular}{|c|c|c|c|c|c|c|c|}
\hline Sample & $\begin{array}{l}\text { Biochar Synthesis } \\
\text { Temperature }\left({ }^{\circ} \mathrm{C}\right)\end{array}$ & $\begin{array}{l}\text { Activating } \\
\text { Reagent }\end{array}$ & $\begin{array}{l}\text { Weight Ratio of } \\
\text { Biochar and } \\
\text { Activating Reagent }\end{array}$ & $\begin{array}{c}\text { BET Surface Area } \\
\left(\mathrm{m}^{2} / \mathrm{g}\right)\end{array}$ & $\begin{array}{c}\text { Langmuir } \\
\text { Surface Area } \\
\left(\mathrm{m}^{2} / \mathrm{g}\right)\end{array}$ & $\begin{array}{l}\text { Pore Volume } \\
\left(\mathrm{cm}^{3} / \mathrm{g}\right)\end{array}$ & $\begin{array}{l}\text { Average Pore } \\
\text { Size (nm) }\end{array}$ \\
\hline $\begin{array}{l}\text { Hemp-Derived } \\
\text { Biochar }\end{array}$ & - & - & - & 2 & 3 & 0.001 & - \\
\hline \multirow{8}{*}{ HAC } & 390 & $\mathrm{KOH}$ & $1: 1$ & 1566 & 2078 & 0.810 & 4.6 \\
\hline & 450 & $\mathrm{KOH}$ & $1: 1$ & 1587 & 2090 & 0.811 & 4.6 \\
\hline & 500 & $\mathrm{KOH}$ & $1: 1$ & 1598 & 2101 & 0.813 & 4.6 \\
\hline & 390 & $\mathrm{KOH}$ & $1: 2$ & 1992 & 2647 & 1.011 & 4.3 \\
\hline & 390 & $\mathrm{KOH}$ & $1: 3$ & 2425 & 3363 & 1.216 & 2.9 \\
\hline & 390 & $\mathrm{NaOH}$ & $1: 1$ & 1252 & 1673 & 0.662 & 4.3 \\
\hline & 390 & $\mathrm{NaOH}$ & $1: 2$ & 1851 & 2525 & 0.925 & 3.1 \\
\hline & 390 & $\mathrm{NaOH}$ & $1: 3$ & 2124 & 2848 & 1.017 & 2.9 \\
\hline
\end{tabular}

Table 2. BET surface areas of activated carbons prepared from different sources of biomass as feedstocks.

\begin{tabular}{ccc}
\hline Biomass Feedstocks & Activator Used & BET Surface Area $\left.\mathbf{( m}^{\mathbf{2}} \mathbf{g}\right)$ \\
\hline Walnut shell [15] & $\mathrm{CO}_{2}$ & 379 \\
Sunflower stem [15] & $\mathrm{CO}_{2}$ & 438 \\
Olive stone [15] & $\mathrm{CO}_{2}$ & 438 \\
Rice husk [16] & $\mathrm{CO}_{2}$ & 446 \\
Glucose/ovalbumin [17] & - & 476 \\
Pinewood [16] & $\mathrm{CO}_{2}$ & 569 \\
Glucose/borax [18] & - & 614 \\
Orange peel [19] & $\mathrm{CO}_{2}$ & 618 \\
Glucose [20] & $\mathrm{KOH}$ & 1197 \\
Palm date seed [21] & $\mathrm{NaOH}$ & 1282 \\
Desert shrub [22] & $\mathrm{ZnCl}$ & 1296 \\
Rice husk [23] & $\mathrm{H}_{3} \mathrm{PO}$ & 1498 \\
Hazelnut shell [24] & $\mathrm{KOH}$ & 1700 \\
Glucose [25] & $\mathrm{KOH}_{4}$ & 1704 \\
Sucrose [26] & $\mathrm{H}_{3} \mathrm{PO}$ & 2120 \\
Glucose [26] & $\mathrm{NaOH}$ & 2129 \\
Starch [27] & $\mathrm{KOH}$ & 2190 \\
Rye straw [28] & $\mathrm{KOH}$ & 2200 \\
Eucalyptus sawdust [29] & $\mathrm{KOH}$ & 2252 \\
Corncobs [30] & $\mathrm{KOH}$ & 2300 \\
Hemp bast fiber (this study) & $\mathrm{KOH}$ & 2425 \\
\hline
\end{tabular}

Figure 1 provides the $\mathrm{N}_{2}$ adsorption-desorption isotherms at $-196{ }^{\circ} \mathrm{C}$ and pore size distributions of $\mathrm{HAC}$, where HACs were prepared using different biochar-to- $\mathrm{KOH}$ ratios at a synthesis temperature of $390^{\circ} \mathrm{C}$. All the adsorption-desorption isotherms exhibit a type IV isotherm with a type IV hysteresis loop (according to IUPAC classification) in the relative pressure range from 0.4 to 1.0. Type IV isotherms are an indication of the existence of well-developed mesopores in the structure, whereas a type IV hysteresis loop indicates the formation of asymmetric, slit-shaped mesopores, attributable to rapid gas evolution and open channels [31]. It has been observed that increasing the ratio of activating agent to biochar increases the textural properties (surface area and pore volume) significantly, attributed to increasing the etching effect of the activating reagent on the biochar surface, thus creating mesopores from micropores [32]. The unique mesoporous structure of HAC contributes to the high specific surface area and uniform pore size distribution. The activation temperature also plays an important role in improving the specific surface area and pore volume. High-temperature activation was shown to enhance porosity as previously confirmed by Wang et al. [11], while low temperatures were not favorable to increasing porosity due to the low reaction rate between the activator and carbonaceous material. Wang et al. [11] obtained the highest BET surface area $\left(2287 \mathrm{~m}^{2} / \mathrm{g}\right)$ for making interconnected carbon nanosheets at $750{ }^{\circ} \mathrm{C}$ during the activation of biochar with $\mathrm{KOH}$. 
The pore size distributions (PSD) of HAC prepared using different biochar-to- $\mathrm{KOH}$ ratios show that all the samples have a very narrow pore size distribution, mainly centered at 3.0 to $4.5 \mathrm{~nm}$. This result is intriguing and indicates highly mesoporous carbon formation. Foo and Hameed [33] reported an average pore size of $21.44 \mathrm{~nm}$ in activated carbon produced from pistachio nut shells via microwave-induced chemical $(\mathrm{KOH})$ activation. The same authors [34] also reported average pore sizes of $34.14 \mathrm{~nm}$ and $26.89 \mathrm{~nm}$ for activated carbon from rice husk as a feedstock using $\mathrm{KOH}$ and $\mathrm{K}_{2} \mathrm{CO}_{3}$ activation. Tay et al. [7] synthesized different types of activated carbon from soybean oil cake and reported an average pore diameter of $5.23 \mathrm{~nm}$ in one of the products.

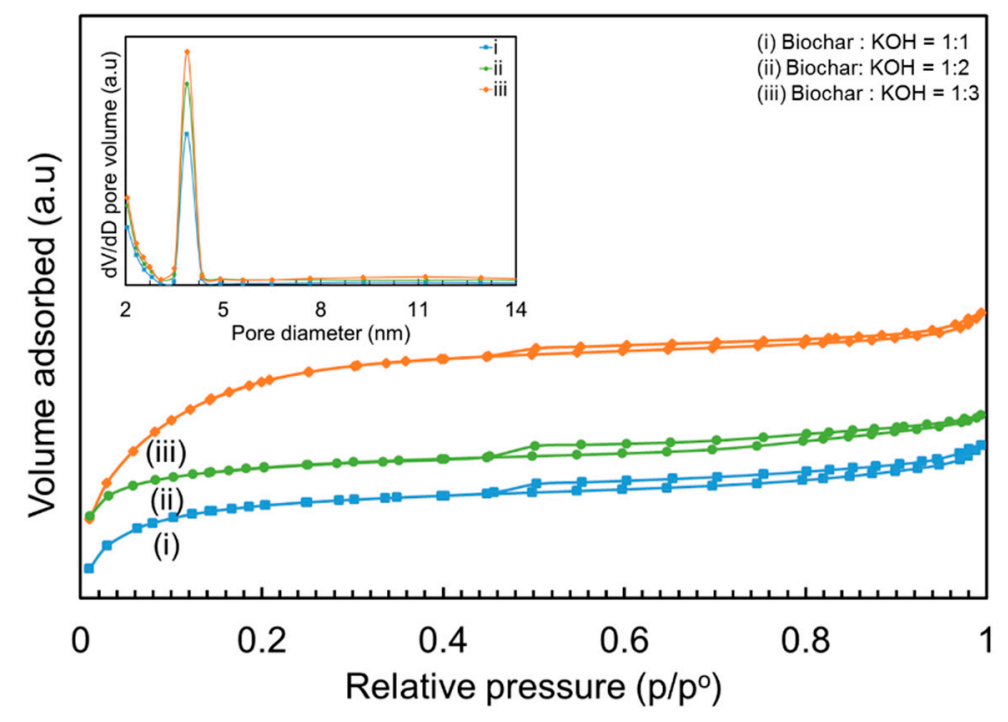

Figure 1. Nitrogen adsorption-desorption isotherms and BJH (Barrett-Joyner-Halenda) pore size distributions of HAC (inset).

The morphology of a material is a crucial factor for its application. The morphology of HAC was investigated and is presented in Figures 2 and 3. Figure 2 shows the SEM images of the obtained hemp biochar (a) and HAC using different ratios of biochar to KOH at 1:1 (b), 1:2 (c), and 1:3 (d). The observed HAC surface morphologies are very different to those from biochar. The biochar surface is rough with irregular sizes of particles and many large defect holes whereas the HAC surface shows the amorphous nature of carbon with a large mesopore content. The differences in morphologies among Figure $2 \mathrm{~b}-\mathrm{d}$ suggest that $\mathrm{KOH}$ plays an important role in pore development of the resultant samples during activation. Figure $3 a$ shows the TEM image of biochar whereas Figure $3 b-d$ show the resulting $\mathrm{HAC}$ using different $\mathrm{KOH}$ ratios. Biochar does not have any pores whereas the activated carbon obtained using different biochar $/ \mathrm{KOH}$ ratios have a regular porous structure. The TEM and SEM images corroborate the BET results. Lu et al. [35] found a similar mesoporous structure (adsorption average pore width $=3.23 \mathrm{~nm}$ ) in activated carbon synthesized from corn straw. The high surface area and mesoporosity of HAC will be useful for gas storage and adsorption applications, and for making carbon foam, supercapacitors, or ultracapacitors, etc., by providing more active sites. 


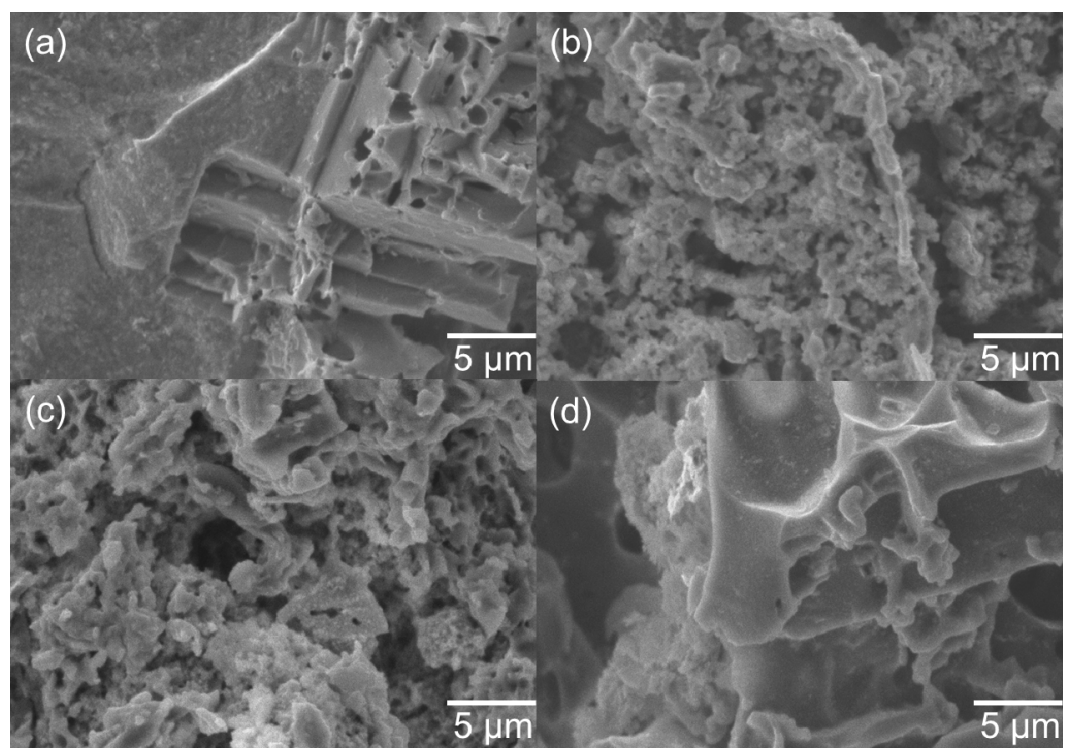

Figure 2. SEM (scanning electron microscopy) images of (a) obtained biochar and HAC obtained using different ratios of biochar to $\mathrm{KOH}((\mathbf{b}) 1: 1 ;$ (c) $1: 2$; (d) $1: 3$ ).

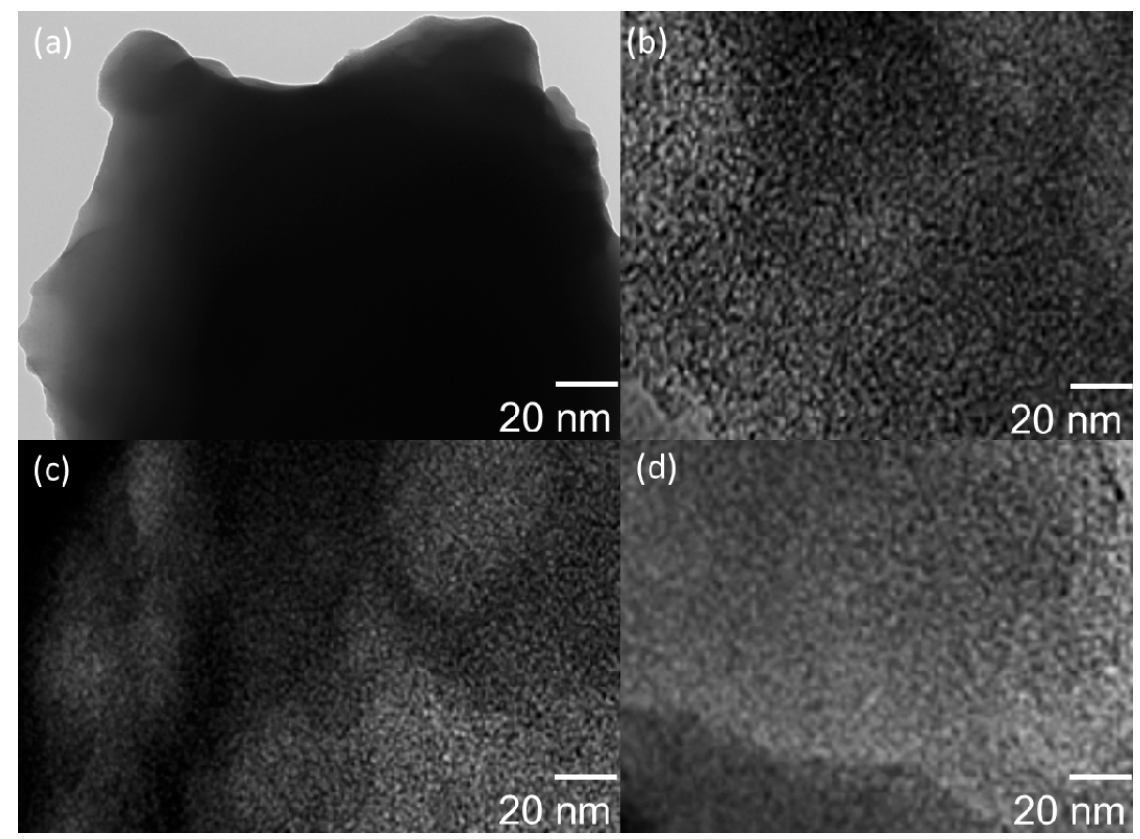

Figure 3. TEM (transmission electron microscopy) images of (a) biochar and HAC obtained using different ratios of biochar to $\mathrm{KOH}((\mathbf{b}) 1: 1 ;$ (c) $1: 2$; (d) $1: 3$ ).

X-ray diffraction (XRD) was used to determine the crystalline structure of HAC. Figure 4 shows the small- and large-angle XRD patterns for the HAC samples. The small-angle XRD pattern for all three samples indicates the formation of an ordered hexagonal mesoporous structure [36]. This type of small-angle XRD peak is completely absent in commercial activated carbon, indicating the lack of a long-range porous structure [37]. The large peak at $23.4^{\circ} 2 \theta(C(002))$ in Figure 4 corresponds to the amorphous carbon structure. The weak and broad $C(100)$ peak at $2 \theta=40-50^{\circ}$ is attributed to the $a$ axis of the graphite structure [38]. The XRD patterns for all three investigated samples are very similar. This suggests that the different ratios of activating agent and biochar do not have a noticeable effect on 
the structural changes of HAC. Similar large-angle XRD patterns were reported by Lu et al. [35] for the synthesis of mesoporous activated carbon from waste biomass material such as corn straw.

The HAC samples were characterized by FTIR (Fourier transform infrared), with the spectra shown in Figure 5. According to the literature [39], the peak at $3288 \mathrm{~cm}^{-1}$ is attributed to O-H stretching while the peaks at $2977 \mathrm{~cm}^{-1}, 2941 \mathrm{~cm}^{-1}, 2914 \mathrm{~cm}^{-1}$, and $2830 \mathrm{~cm}^{-1}$ are ascribed to asymmetric $\mathrm{CH}_{3}$, asymmetric $\mathrm{CH}_{2}$, symmetric $\mathrm{CH}_{3}$, and symmetric $\mathrm{CH}_{2}$ stretching modes. The peak at $1447 \mathrm{~cm}^{-1}$ is attributable to $\mathrm{CH}_{2}$ scissoring and $\mathrm{CH}_{3}$ asymmetric bending modes. The peak at $1402 \mathrm{~cm}^{-1}$ can be assigned to $\mathrm{O}-\mathrm{H}$ in-plane bending and $\mathrm{CH}_{3}$ umbrella modes. The peak at $1109 \mathrm{~cm}^{-1}$ is attributable to $\mathrm{CH}_{3}$ rocking or $\mathrm{CH}_{2}$ wagging modes. The peak at $1016 \mathrm{~cm}^{-1}$ is mainly attributed to alcoholic $\mathrm{C}-\mathrm{O}$ stretching mode. No significant difference is observed among the spectra of these samples, suggesting similar surface functional groups regardless of the biochar-to- $\mathrm{KOH}$ ratio. The presence of such functional groups was also reported by Barkauskas et al. [40] for commercial granulated activated carbon.

Raman spectroscopy was used to examine the ordered and disordered crystal structures of the HAC. Figure 6 compares the Raman spectra of hemp-derived activated carbon samples collected using a $785 \mathrm{~nm}$ laser. In these spectra, the $\mathrm{G}$ band at $1588 \mathrm{~cm}^{-1}$ corresponds to the first-order scattering of $E_{2 g}$ mode and is related to the vibration of $\mathrm{sp}^{2}$-bonded carbon atoms. The $\mathrm{D}$ band at $1315 \mathrm{~cm}^{-1}$ arises from a breathing mode of $k$-point phonons of $\mathrm{A}_{1 \mathrm{~g}}$ symmetry [41]. The $\mathrm{D}$ band corresponds to the amount of disorder and its intensity shows a degree of edge chirality [42]. By deconvoluting these peaks, the intensity ratios of $\mathrm{D} / \mathrm{G}\left(\mathrm{I}_{\mathrm{D}} / \mathrm{I}_{\mathrm{G}}\right)$ were calculated and are listed in Table 3 . The samples from the ratios of biochar to $\mathrm{KOH}$ at $1: 1$ and 1:2 demonstrated the same intensity ratio $\left(\mathrm{I}_{\mathrm{D}} / \mathrm{I}_{\mathrm{G}}\right)$ of 1.37 , which is lower than that (1.44) obtained from the ratio of biochar to $\mathrm{KOH}$ at 1:3. High $\mathrm{I}_{\mathrm{D}} / \mathrm{I}_{\mathrm{G}}$ ratios suggest a high level of disorder such as defects, ripples, and edges [43]. Besides this, the full width at half-maximum (FWHM) of the G band $\left(\Gamma_{\mathrm{G}}\right)$ increased from $92.8 \mathrm{~cm}^{-1}$ to $111.7 \mathrm{~cm}^{-1}$ when the ratio of biochar to $\mathrm{KOH}$ decreased from 1:1 to 1:3. As reviewed by Maslova et al. [44], higher $\Gamma_{\mathrm{G}}$ represents a larger amount of defects for carbonaceous materials.

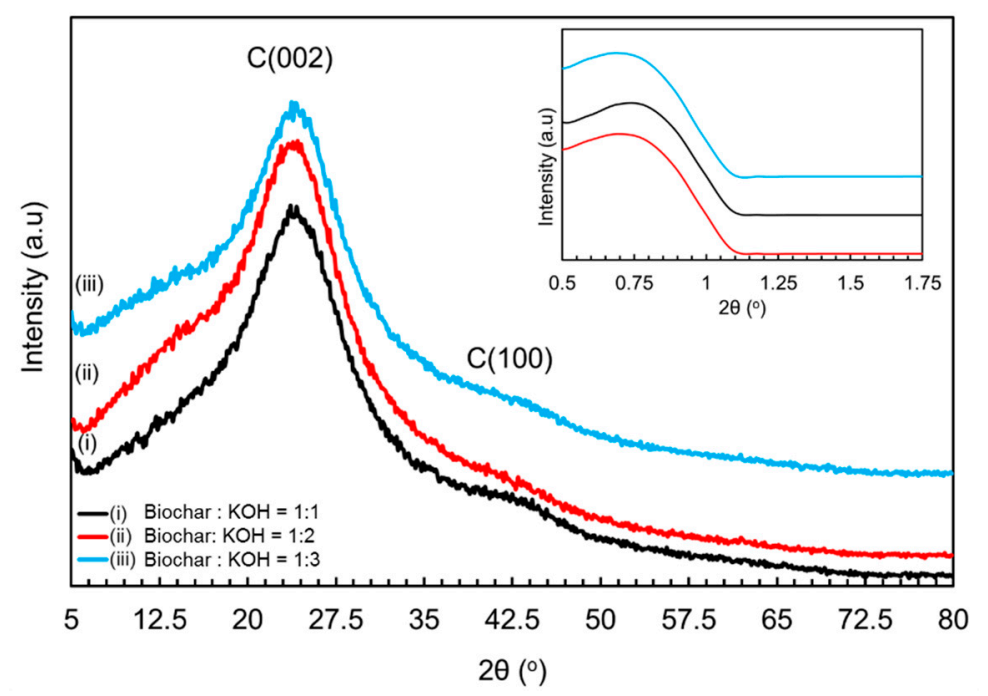

Figure 4. Large-angle and small-angle (inset) XRD patterns of the HAC. 


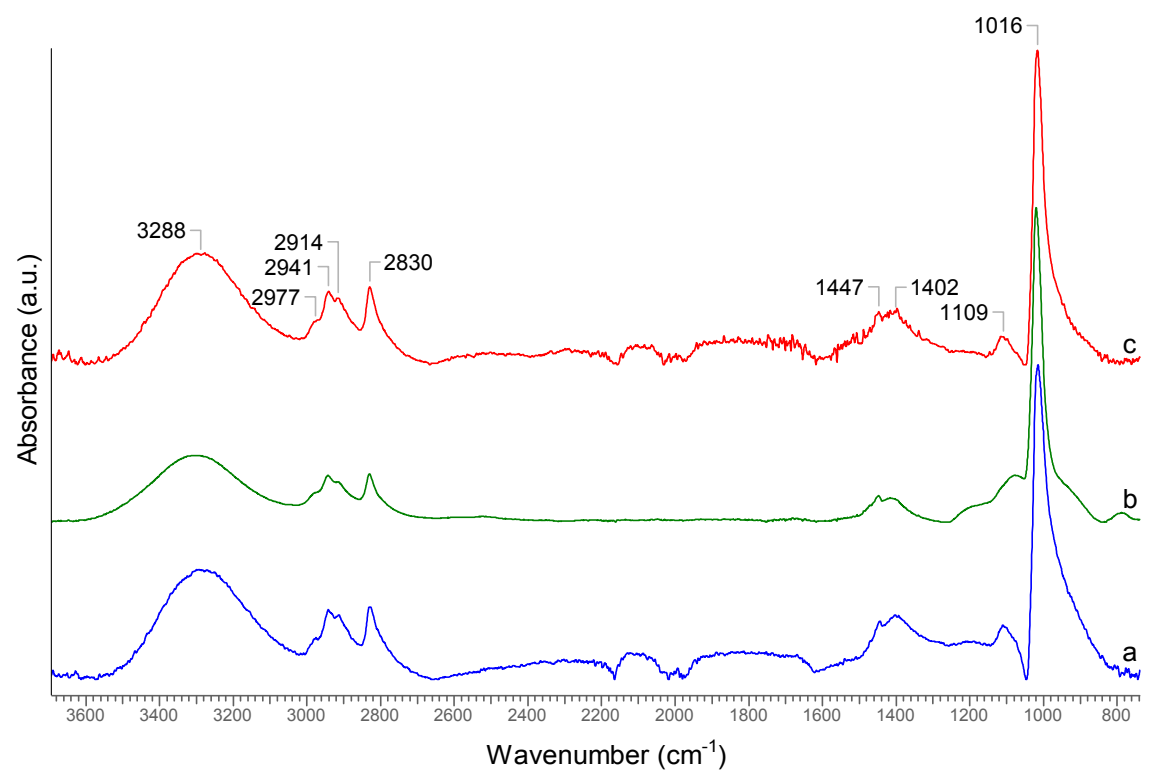

Figure 5. ATR-FTIR (Attenuated total reflectance-Fourier transform infrared) spectra of hemp-derived activated carbon at different biochar and $\mathrm{KOH}$ ratios ((a) 1:1, (b) 1:2, and (c) 1:3).

It has been reported that the crystallite domain size (La) of carbonaceous materials can be calculated using the equation $\mathrm{La}=\mathrm{C}\left(\lambda_{\mathrm{L}}\right) /\left(\mathrm{I}_{\mathrm{D}} / \mathrm{I}_{\mathrm{G}}\right)$ where a linear relationship $\mathrm{C}\left(\lambda_{\mathrm{L}}\right) \approx \mathrm{C}_{0}+\lambda_{\mathrm{L}} \mathrm{C}_{1}$ is valid in the excitation wavelength range of $400 \mathrm{~nm}<\lambda_{\mathrm{L}}<700 \mathrm{~nm}$ where $\mathrm{C}_{0}=-12.6 \mathrm{~nm}$ and $\mathrm{C}_{1}=0.033$ [45]. In order to study the domain size of the HAC samples, the Raman spectra of these samples were also collected using two other laser sources with respective wavelengths of $633 \mathrm{~nm}$ and $514 \mathrm{~nm}$. The $\mathrm{I}_{\mathrm{D}} / \mathrm{I}_{\mathrm{G}}$ and La values were calculated and are listed in Table 3. According to these results, the domain sizes of the samples obtained from biochar to $\mathrm{KOH}$ ratios of 1:1 and 1:2 are similar, but larger than those obtained using a biochar-to- $\mathrm{KOH}$ ratio of 1:3. These results are in good agreement with the Raman results measured using the $785 \mathrm{~nm}$ laser, i.e., the crystallite domain size did not change much when the ratio of biochar to $\mathrm{KOH}$ changed from 1:1 to 1:2, but decreased when the ratio of biochar to $\mathrm{KOH}$ changed to 1:3.

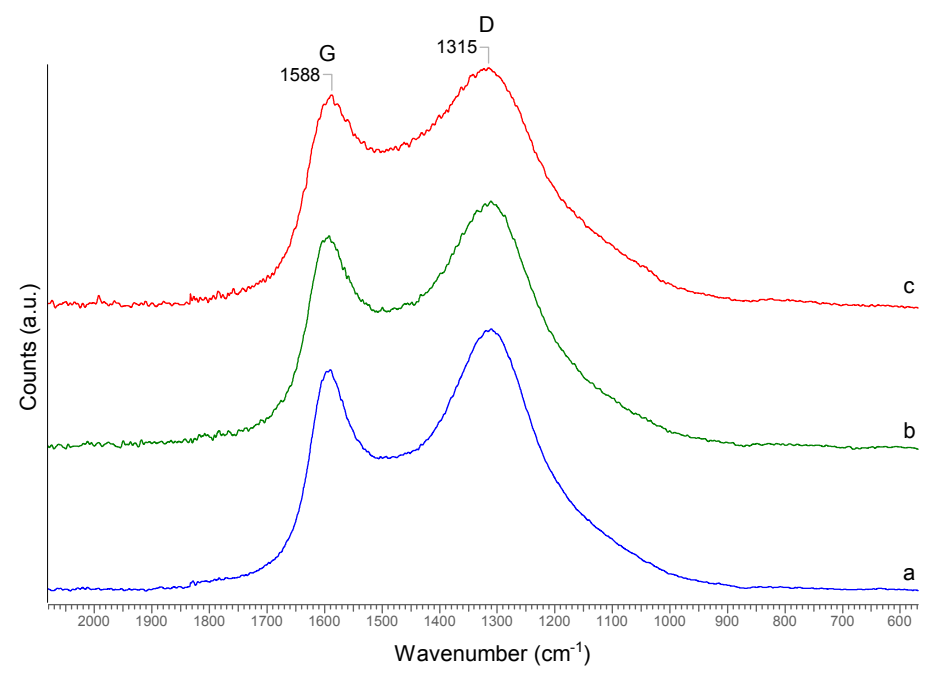

Figure 6. Raman spectra of hemp-derived activated carbon at different biochar and $\mathrm{KOH}$ ratios ((a) 1:1, (b) $1: 2$, and (c) 1:3). 
Table 3. Raman results of the HAC samples obtained from different biochar-to-KOH ratios.

\begin{tabular}{ccccccc}
\hline \multirow{2}{*}{ Ratios } & \multicolumn{2}{c}{$\lambda=\mathbf{7 8 5} \mathbf{n m}$} & \multicolumn{2}{c}{$\lambda=\mathbf{6 3 3} \mathbf{~ n m}$} & \multicolumn{2}{c}{$\lambda=\mathbf{5 1 4} \mathbf{n m}$} \\
\cline { 2 - 7 } & $\mathbf{I}_{\mathbf{D}} / \mathbf{I}_{\mathbf{G}}$ & $\boldsymbol{\Gamma}_{\mathbf{G}}\left(\mathbf{c m}^{-\mathbf{1}}\right)$ & $\mathbf{I}_{\mathbf{D}} / \mathbf{I}_{\mathbf{G}}$ & $\mathbf{L a}(\mathbf{n m})$ & $\mathbf{I}_{\mathbf{D}} / \mathbf{I}_{\mathbf{G}}$ & La (nm) \\
\hline $1: 1$ & 1.37 & 92.8 & $1.112 \pm 0.007$ & $7.46 \pm 0.05$ & $1.008 \pm 0.043$ & $4.33 \pm 0.18$ \\
$1: 2$ & 1.37 & 102.2 & $1.105 \pm 0.035$ & $7.50 \pm 0.24$ & $1.028 \pm 0.017$ & $4.24 \pm 0.07$ \\
$1: 3$ & 1.44 & 111.7 & $1.191 \pm 0.016$ & $6.96 \pm 0.09$ & $1.071 \pm 0.020$ & $4.07 \pm 0.08$ \\
\hline
\end{tabular}

The surface chemistry of HAC was characterized using X-ray photoelectron spectroscopy (XPS). XPS survey spectra of HACs are summarized in Figure 7a and Table 4. Figure 7a and Table 4 show that increasing the biochar-to- $\mathrm{KOH}$ ratio increases the atomic percentages of $\mathrm{O}$ (from $16.6 \%$ to $24.2 \%$ ) and decreases the atomic percentages of C (80\% to 70.7\%). Similar trends were confirmed by Tai et al. [46] for synthesizing activated carbon from graphite using different $\mathrm{KOH}$ ratios. The atomic percentage of $\mathrm{Si}$ also slightly increased (from $2.3 \%$ to $4.2 \%$ ) with increasing ratios. Si is the second most abundant element in soils which is found in substantial amounts in many plants [47]. Higher amounts of $\mathrm{KOH}$ helped to precipitate higher Si on the surface of HAC.
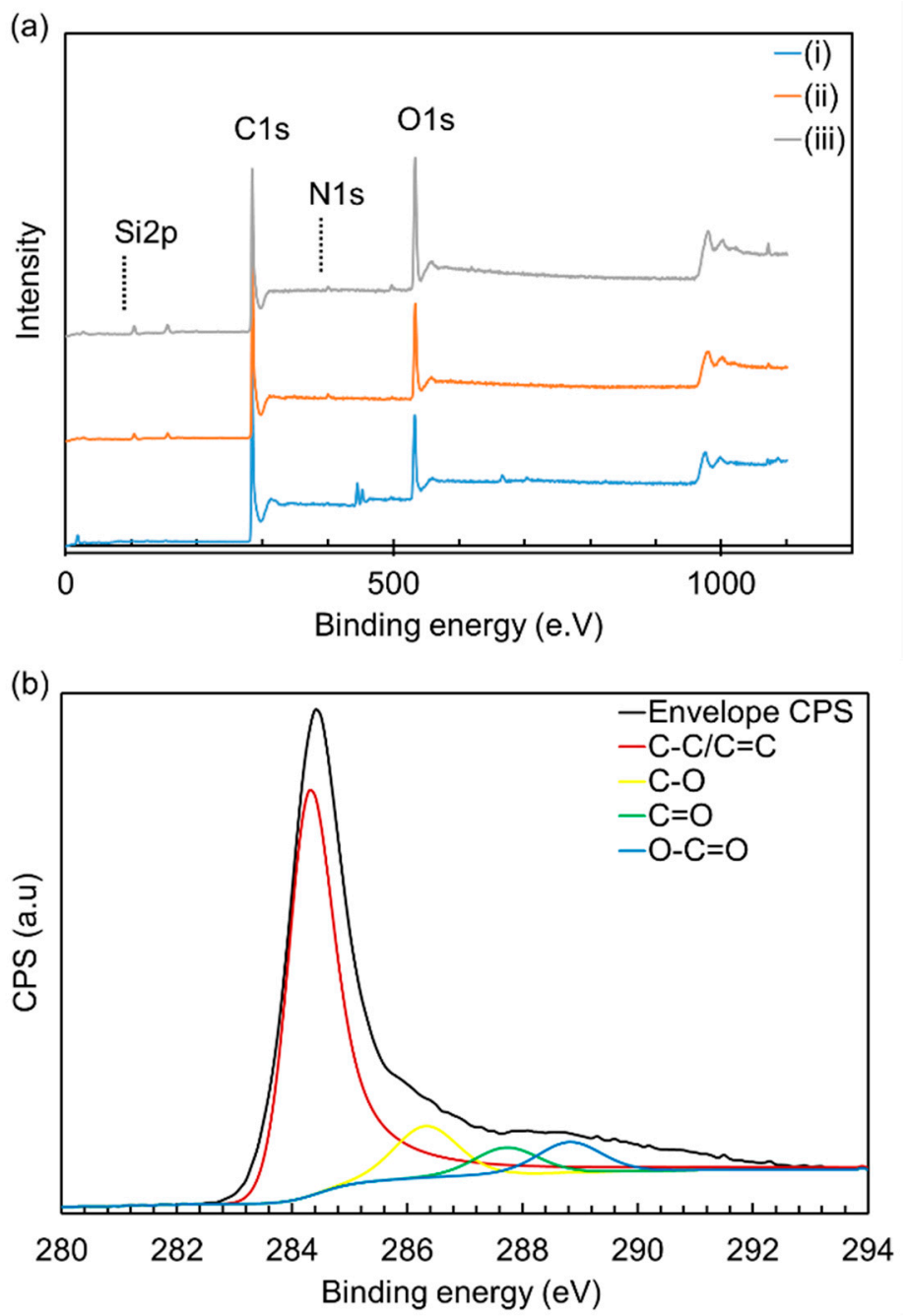

Figure 7. Cont. 

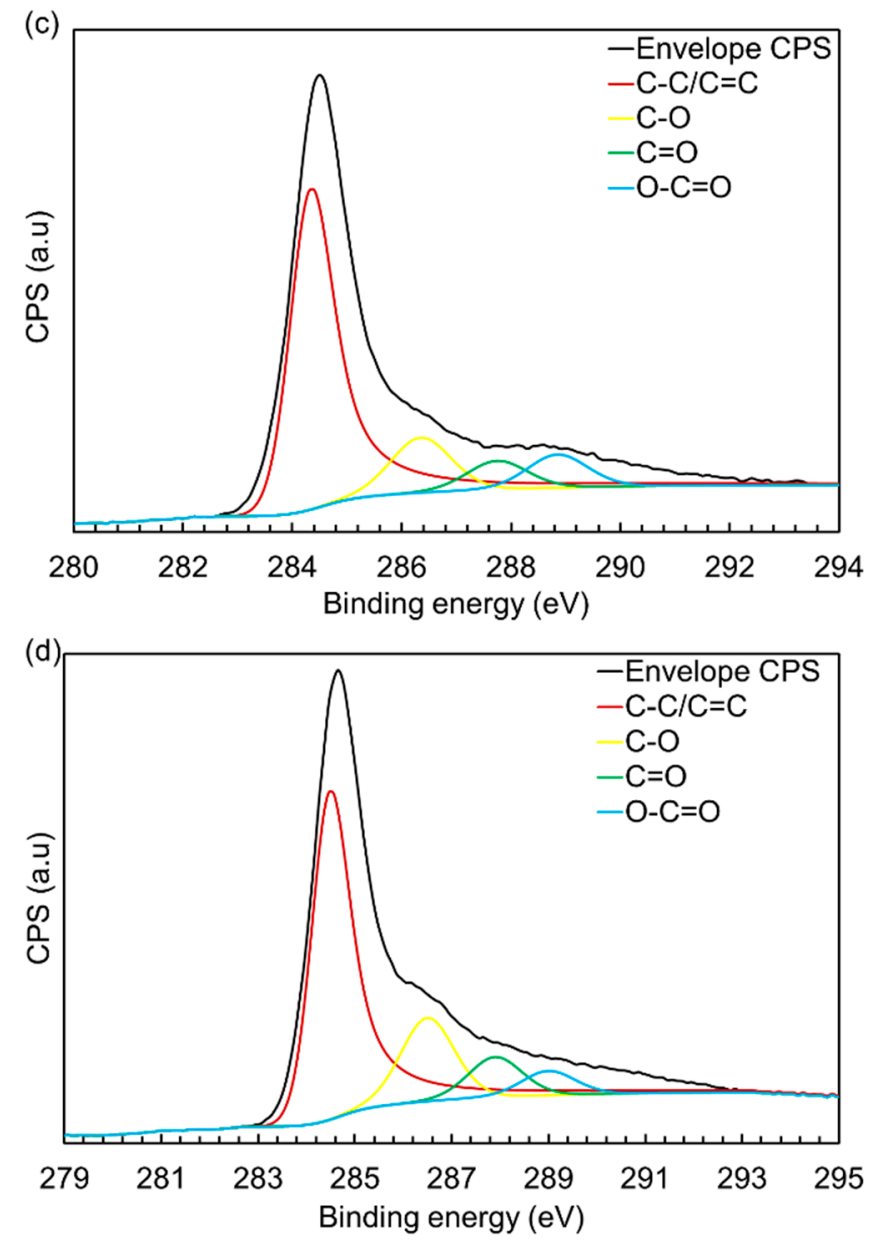

Figure 7. (a) XPS survey spectra of HAC obtained using different ratios of biochar to KOH. (i) 1:1; (ii) 1:2; (iii) 1:3. High-resolution C(1s) XPS spectra of resultant HAC obtained using different ratios of biochar to KOH. (b) $1: 1 ;$ (c) $1: 2 ;$ (d) $1: 3$.

Table 4. Atomic percentages of the elements present in the surfaces of carbonaceous materials with different biochar-to- $\mathrm{KOH}$ ratios.

\begin{tabular}{ccccc}
\hline Ratios & \multicolumn{5}{c}{ Atomic Percentages } \\
\hline & $\mathbf{C}$ & $\mathbf{O}$ & $\mathbf{N}$ & Si \\
\hline $1: 1$ & 80.0 & 16.6 & 1.1 & 2.3 \\
$1: 2$ & 73.1 & 22.4 & 1.1 & 3.4 \\
$1: 3$ & 70.7 & 24.2 & 0.9 & 4.2 \\
\hline
\end{tabular}

The C(1s) XPS spectra of the resultant HAC are shown in Figure $7 \mathrm{~b}-\mathrm{d}$ with the four most prominent deconvoluted components of the $C(1 s)$ envelope shown in each panel. Relative contents of carbon species present in HACs based on the XPS survey spectra are presented in Table 5. The binding energy of $284.5 \mathrm{eV}$ is attributed to the $\mathrm{C}-\mathrm{C}, \mathrm{C}=\mathrm{C}$, and $\mathrm{C}-\mathrm{H}$ bonds. Moreover, the binding energies of $286.4 \mathrm{eV}$, $287.8 \mathrm{eV}$, and $289.1 \mathrm{eV}$ are typically assigned to the $\mathrm{C}-\mathrm{OH}, \mathrm{C}=\mathrm{O}$, and $\mathrm{O}=\mathrm{C}-\mathrm{OH}$ functional groups, respectively [48]. Deconvolution of all the $\mathrm{C}(1 \mathrm{~s})$ spectra resulted in a main peak located at $284.4 \mathrm{eV}$, corresponding to the $\mathrm{C}-\mathrm{C}, \mathrm{C}=\mathrm{C}$, and $\mathrm{C}-\mathrm{H}$ bonds. In Figure $7 \mathrm{~b}-\mathrm{d}$, deconvolution of the $\mathrm{C}(1 \mathrm{~s})$ peak of the $\mathrm{HAC}$ resulted in three peaks located at binding energies of $286.4 \mathrm{eV}, 287.8 \mathrm{eV}$, and $289.1 \mathrm{eV}$, which are attributed to the $\mathrm{C}-\mathrm{OH}, \mathrm{C}=\mathrm{O}$, and $\mathrm{O}=\mathrm{C}-\mathrm{OH}$ functional groups, respectively. Usually, the $\mathrm{C}(1 \mathrm{~s}) \mathrm{XPS}$ spectrum of commercial activated carbon shows four similar components that correspond to carbon 
atoms in different functional groups: the non-oxygenated $\mathrm{C}$ at $284.5 \mathrm{eV}$ for $\mathrm{C}=\mathrm{C} / \mathrm{C}-\mathrm{C}$ in aromatic rings, the $\mathrm{C}$ in $\mathrm{C}-\mathrm{O}$ bonds at $286.4 \mathrm{eV}$ for epoxy and alkoxy, the carbonyl $\mathrm{C}$ at $287.8 \mathrm{eV}$ for $\mathrm{C}=\mathrm{O}$, and the carboxylate carbon at $289.1 \mathrm{eV}$ for $\mathrm{O}-\mathrm{C}=\mathrm{O}$ [49]. Relative percentages of oxygenated functional groups increase with increasing biochar-to- $\mathrm{KOH}$ ratios, whereas the nonoxygenated functional group slightly decreases (Table 5). The values obtained in Table 5 for HAC samples are comparable with the values for several commercial activated charcoals such as Superchar, Darco KB-B, Norit B Supra, and Norit U.S.P. XX [50].

Table 5. Relative contents of carbon species present in the carbonaceous materials based on XPS survey spectra.

\begin{tabular}{cccccc}
\hline Samples & Ratios & \multicolumn{4}{c}{ Percentages of Relative Content } \\
\hline & & C-C/C=C & C-O & C=O & O-C=O \\
\hline \multirow{2}{*}{ HAC } & $1: 1$ & 78.3 & 10.3 & 5.4 & 6.0 \\
& $1: 2$ & 76.1 & 11.2 & 5.9 & 6.8 \\
SuperChar & $1: 3$ & 75.1 & 12.2 & 6.5 & 6.2 \\
Darco KB-B & - & 73.4 & 15.7 & 5.7 & 5.1 \\
Norit B Supra & - & 78.1 & 12.8 & 6.2 & 2.9 \\
Norit U.S.P. XX & - & 78.6 & 15.1 & 2.6 & 3.7 \\
\hline
\end{tabular}

TG-DTA (Thermogravimetric and differential thermal analysis) of HAC under nitrogen atmosphere was investigated for thermal stability, which is shown in Figure 8. An approximately $20 \mathrm{wt} \%$ mass loss was detected when the material was heated up to $1000{ }^{\circ} \mathrm{C}$. Derivative weight loss curves showed that the loss was occurred at $<200{ }^{\circ} \mathrm{C}$, which was attributed to the loss of absorbed moisture.

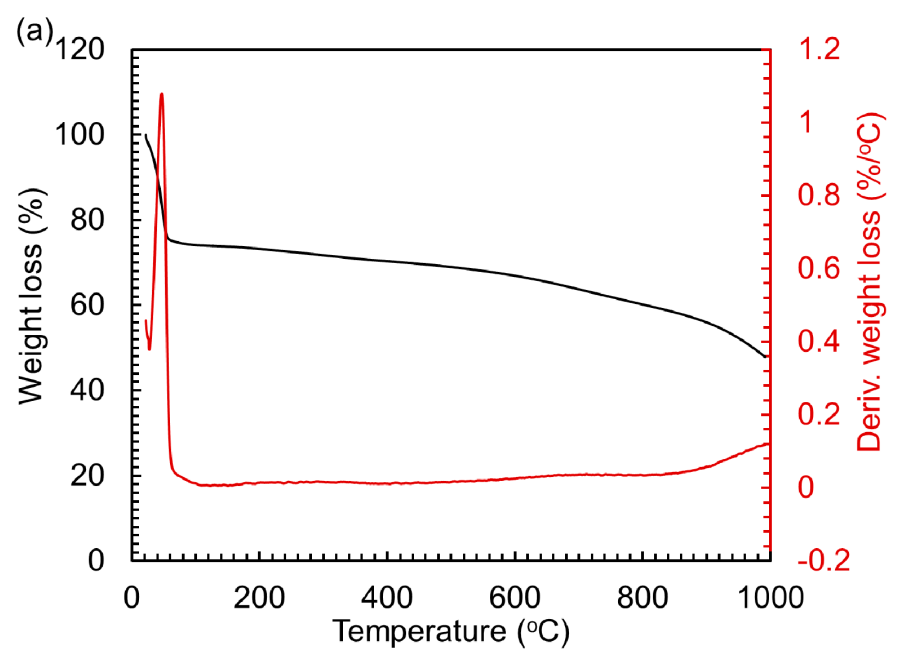

Figure 8. Cont. 

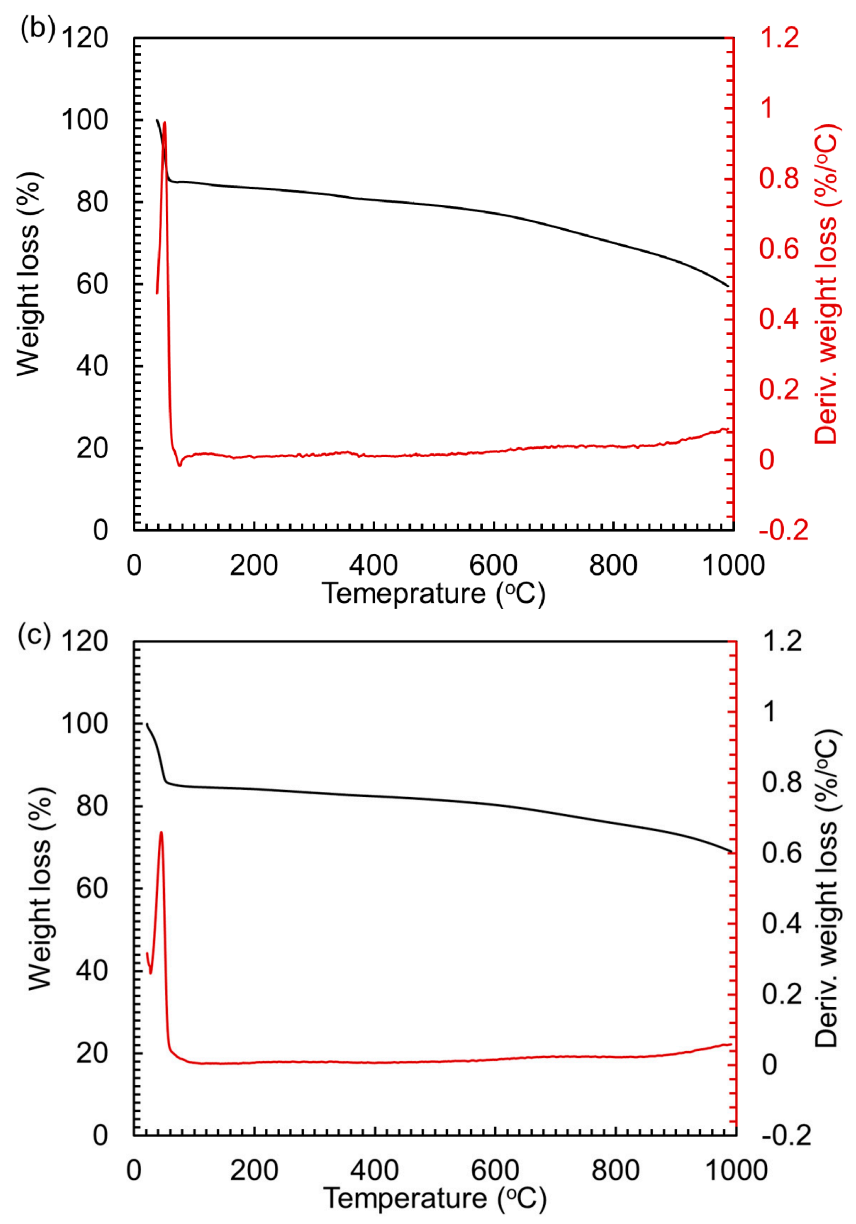

Figure 8. TG-DTA (Thermogravimetric and differential thermal analysis) curves for hemp-derived activated carbon obtained using different ratios of biochar to $\mathrm{KOH}((\mathbf{a}) 1: 1,(\mathbf{b}) 1: 2$, and (c) 1:3).

Oxygenated functional groups in the surface of carbon material are presumed to be the main active sites. HAC has oxygenated surface functional groups and high thermal stability, so can be used as catalysts for high-temperature applications such as pyrolysis, gasification, hydrodeoxygenation, or decarboxylation processes.

As shown above, both $\mathrm{KOH}$ and $\mathrm{NaOH}$ provide high-surface-area activated carbon from hemp fiber biochar. Both $\mathrm{KOH}$ and $\mathrm{NaOH}$ are believed to act as dehydrating agents which influence the pyrolytic decomposition and inhibit the formation of tar, thus enhancing the yield of carbon. Impregnation of $\mathrm{KOH}$ into the biochar first results in degradation of the cellulosic material and then carbonization, leading to dehydration that results in charring and aromatization of the carbon skeleton and creation of the porous structure [51]. A pore structure with resultant high surface area is formed by the rigorous evolution of gaseous by-products during $\mathrm{KOH}$ activation. According to the chemical activation mechanism [52,53], it is suggested that during activation, the chemical reaction between $\mathrm{KOH}$ and carbon proceeds as $6 \mathrm{KOH}+2 \mathrm{C}=2 \mathrm{~K}+3 \mathrm{H}_{2}+2 \mathrm{~K}_{2} \mathrm{CO}_{3}$; followed by either decomposition of $\mathrm{K}_{2} \mathrm{CO}_{3}$ or reaction of $\mathrm{K} / \mathrm{K}_{2} \mathrm{CO}_{3} / \mathrm{CO}_{2}$ with carbon, the production of $\mathrm{H}_{2}$ will potentially open up the pores. More importantly, according to Viculis et al. [54], potassium might play an important role in greatly increasing the surface area. The produced potassium atoms form an intercalation compound, $\mathrm{KC}_{8}$. Upon treatment with water after activation, the reaction between potassium intercalated compounds and aqueous solvent opens up the pores [54]. As shown in Table 1, it was found that with increased $\mathrm{KOH}$ loading in the activation reaction, the surface area of the resulting product increased, being consistent with this mechanism. 


\section{Conclusions}

$>$ Hemp-fiber-derived highly mesoporous activated carbon (HAC) with large surface area and pore volume was synthesized.

$>$ The final product was found to be insensitive to the synthesis temperature of the intermediate product (biochar).

$>$ Surface morphologies of HAC were confirmed using several physicochemical techniques such as BET, SEM, TEM, XRD, FTIR, Raman, and XPS analysis.

Supplementary Materials: The following is available online at http:/ /www.mdpi.com/2311-5629/4/3/38/s1, Table S1: BET surface area of some commercial products.

Author Contributions: M.Z.H. performed the experimental works and wrote the manuscript. W.W., W.Z.X., M.B.I.C., A.K.J. and D.M. conducted FTIR, Raman, BET, XRD, and SEM analysis, respectively. P.A.C. supervised the whole work and reviewed the manuscript. All authors reviewed the manuscript prior to submission.

Funding: This work is financed by Natural Sciences \& Engineering Research Councils (NSERC) of Canada \& BioFuelNet Canada.

Acknowledgments: We thank Mark C. Biesinger of Western Surface Science for XPS analysis.

Conflicts of Interest: The authors declare no conflict of interest. The funding sponsors had no role in the design of the study; in the collection, analyses, or interpretation of data; in the writing of the manuscript, and in the decision to publish the results.

\section{References}

1. Jain, A.; Balasubramanian, R.; Srinivasan, M. Hydrothermal conversion of biomass waste to activated carbon with high porosity: A review. Chem. Eng. J. 2016, 283, 789-805. [CrossRef]

2. Li, X.; Liu, S.; Huang, Y.; Zheng, Y.; Harper, D.P.; Zheng, Z. Preparation and Foaming Mechanism of Pyrocarbon Foams Controlled by Activated Carbon as the Transplantation Core. ACS Sustain. Chem. Eng. 2018, 6, 3515-3524. [CrossRef]

3. Kim, M.-H.; Kim, K.-B.; Park, S.-M.; Roh, K.C. Hierarchically structured activated carbon for ultracapacitors. Sci. Rep. 2016, 6, 21182. [CrossRef] [PubMed]

4. Ba, H.; Wang, W.; Pronkin, S.; Romero, T.; Baaziz, W.; Nguyen-Dinh, L.; Chu, W.; Ersen, O.; Pham-Huu, C. Biosourced Foam-Like Activated Carbon Materials as High-Performance Supercapacitors. Adv. Sustain. Syst. 2018, 2. [CrossRef]

5. Bansal, R.; Donnet, J.; Stoeckli, F. Active Carbon; Marcell Dekker: New York, NY, USA, 1988.

6. Bardestani, R.; Kaliaguine, S. Steam activation and mild air oxidation of vacuum pyrolysis biochar. Biomass Bioenergy 2018, 108, 101-112. [CrossRef]

7. Tay, T.; Ucar, S.; Karagöz, S. Preparation and characterization of activated carbon from waste biomass. J. Hazard. Mater. 2009, 165, 481-485. [CrossRef] [PubMed]

8. Li, S.; Han, K.; Li, J.; Li, M.; Lu, C. Preparation and characterization of super activated carbon produced from gulfweed by KOH activation. Microporous Mesoporous Mater. 2017, 243, 291-300. [CrossRef]

9. Afdhol, M.; Amiliana, R.; Hanafi, A. Preparation of Activated Carbon from Palm Shells Using KOH and $\mathrm{ZnC}_{12}$ as the Activating Agent. In Proceedings of the IOP Conference Series: Earth and Environmental Science, Iasi, Romania, 17-18 May 2018.

10. Hemp Fibres Better Than Graphene. Available online: http://www.bbc.com/news/science-environment28770876 (accessed on 19 April 2018).

11. Wang, H.; Xu, Z.; Kohandehghan, A.; Li, Z.; Cui, K.; Tan, X.; Stephenson, T.; King'ondu, C.K.; Holt, C.M.B.; Olsen, B.C.; et al. Interconnected Carbon Nanosheets Derived from Hemp for Ultrafast Supercapacitors with High Energy. ACS Nano 2013, 7, 5131-5141. [CrossRef] [PubMed]

12. Yang, R.; Liu, G.; Xu, X.; Li, M.; Zhang, J.; Hao, X. Surface texture, chemistry and adsorption properties of acid blue 9 of hemp (Cannabis sativa L.) bast-based activated carbon fibers prepared by phosphoric acid activation. Biomass Bioenergy 2011, 35, 437-445. [CrossRef]

13. Rosas, J.; Bedia, J.; Rodríguez-Mirasol, J.; Cordero, T. HEMP-derived activated carbon fibers by chemical activation with phosphoric acid. Fuel 2009, 88, 19-26. [CrossRef] 
14. Subramanian, V.; Luo, C.; Stephan, A.; Nahm, K.; Thomas, S.; Wei, B. Supercapacitors from activated carbon derived from banana fibers. J. Phys. Chem. C 2007, 111, 7527-7531. [CrossRef]

15. Roman, S.; Nabais, J.V.; Ledesma, B.; González, J.; Laginhas, C.; Titirici, M. Production of low-cost adsorbents with tunable surface chemistry by conjunction of hydrothermal carbonization and activation processes. Microporous Mesoporous Mater. 2013, 165, 127-133. [CrossRef]

16. Liu, Z.; Zhang, F.-S. Removal of copper(II) and phenol from aqueous solution using porous carbons derived from hydrothermal chars. Desalination 2011, 267, 101-106. [CrossRef]

17. White, R.J.; Yoshizawa, N.; Antonietti, M.; Titirici, M.-M. A sustainable synthesis of nitrogen-doped carbon aerogels. Green Chem. 2011, 13, 2428-2434. [CrossRef]

18. Fellinger, T.P.; White, R.J.; Titirici, M.M.; Antonietti, M. Borax-Mediated Formation of Carbon Aerogels from Glucose. Adv. Funct. Mater. 2012, 22, 3254-3260. [CrossRef]

19. Fernandez, M.; Ledesma, B.; Román, S.; Bonelli, P.; Cukierman, A. Development and characterization of activated hydrochars from orange peels as potential adsorbents for emerging organic contaminants. Bioresour. Technol. 2015, 183, 221-228. [CrossRef] [PubMed]

20. Gao, F.; Shao, G.; Qu, J.; Lv, S.; Li, Y.; Wu, M. Tailoring of porous and nitrogen-rich carbons derived from hydrochar for high-performance supercapacitor electrodes. Electrochim. Acta 2015, 155, 201-208. [CrossRef]

21. Islam, M.A.; Tan, I.; Benhouria, A.; Asif, M.; Hameed, B. Mesoporous and adsorptive properties of palm date seed activated carbon prepared via sequential hydrothermal carbonization and sodium hydroxide activation. Chem. Eng. J. 2015, 270, 187-195. [CrossRef]

22. Zhu, X.; Liu, Y.; Qian, F.; Zhou, C.; Zhang, S.; Chen, J. Role of hydrochar properties on the porosity of hydrochar-based porous carbon for their sustainable application. ACS Sustain. Chem. Eng. 2015, 3, 833-840. [CrossRef]

23. Ding, L.; Zou, B.; Li, Y.; Liu, H.; Wang, Z.; Zhao, C.; Su, Y.; Guo, Y. The production of hydrochar-based hierarchical porous carbons for use as electrochemical supercapacitor electrode materials. Coll. Surf. A Physicochem. Eng. Asp. 2013, 423, 104-111. [CrossRef]

24. Unur, E.; Brutti, S.; Panero, S.; Scrosati, B. Nanoporous carbons from hydrothermally treated biomass as anode materials for lithium ion batteries. Microporous Mesoporous Mater. 2013, 174, 25-33. [CrossRef]

25. Gong, Y.; Wang, H.; Wei, Z.; Xie, L.; Wang, Y. An efficient way to introduce hierarchical structure into biomass-based hydrothermal carbonaceous materials. ACS Sustain. Chem. Eng. 2014, 2, 2435-2441. [CrossRef]

26. Romero-Anaya, A.J.; Ouzzine, M.; Lillo-Ródenas, M.; Linares-Solano, A. Spherical carbons: Synthesis, characterization and activation processes. Carbon 2014, 68, 296-307. [CrossRef]

27. Sevilla, M.; Fuertes, A.B. Sustainable porous carbons with a superior performance for $\mathrm{CO}_{2}$ capture. Energy Environ. Sci. 2011, 4, 1765-1771. [CrossRef]

28. Falco, C.; Marco-Lozar, J.P.; Salinas-Torres, D.; Morallon, E.; Cazorla-Amorós, D.; Titirici, M.-M.; Lozano-Castelló, D. Tailoring the porosity of chemically activated hydrothermal carbons: Influence of the precursor and hydrothermal carbonization temperature. Carbon 2013, 62, 346-355. [CrossRef]

29. Sevilla, M.; Fuertes, A.; Mokaya, R. High density hydrogen storage in superactivated carbons from hydrothermally carbonized renewable organic materials. Energy Environ. Sci. 2011, 4, 1400-1410. [CrossRef]

30. Falco, C.; Sieben, J.M.; Brun, N.; Sevilla, M.; Van der Mauelen, T.; Morallón, E.; Cazorla-Amorós, D.; Titirici, M.M. Hydrothermal Carbons from Hemicellulose-Derived Aqueous Hydrolysis Products as Electrode Materials for Supercapacitors. ChemSusChem 2013, 6, 374-382. [CrossRef] [PubMed]

31. Yang, S.-Y.; Chang, K.-H.; Huang, Y.-L.; Lee, Y.-F.; Tien, H.-W.; Li, S.-M.; Lee, Y.-H.; Liu, C.-H.; Ma, C.-C.M.; $\mathrm{Hu}, \mathrm{C}$.-C. A powerful approach to fabricate nitrogen-doped graphene sheets with high specific surface area. Electrochem. Commun. 2012, 14, 39-42. [CrossRef]

32. Islam, M.A.; Ahmed, M.; Khanday, W.; Asif, M.; Hameed, B. Mesoporous activated carbon prepared from $\mathrm{NaOH}$ activation of rattan (Lacosperma secundiflorum) hydrochar for methylene blue removal. Ecotoxicol. Environ. Saf. 2017, 138, 279-285. [CrossRef] [PubMed]

33. Foo, K.; Hameed, B. Preparation and characterization of activated carbon from pistachio nut shells via microwave-induced chemical activation. Biomass Bioenergy 2011, 35, 3257-3261. [CrossRef]

34. Foo, K.; Hameed, B. Utilization of rice husks as a feedstock for preparation of activated carbon by microwave induced $\mathrm{KOH}$ and $\mathrm{K}_{2} \mathrm{CO}_{3}$ activation. Bioresour. Technol. 2011, 102, 9814-9817. [CrossRef] [PubMed] 
35. Lu, Y.; Zhang, S.; Yin, J.; Bai, C.; Zhang, J.; Li, Y.; Yang, Y.; Ge, Z.; Zhang, M.; Wei, L. Mesoporous activated carbon materials with ultrahigh mesopore volume and effective specific surface area for high performance supercapacitors. Carbon 2017, 124, 64-71. [CrossRef]

36. Zhao, D.; Feng, J.; Huo, Q.; Melosh, N.; Fredrickson, G.H.; Chmelka, B.F.; Stucky, G.D. Triblock copolymer syntheses of mesoporous silica with periodic 50 to 300 angstrom pores. Science 1998, 279, 548-552. [CrossRef] [PubMed]

37. Zou, L.; Li, L.; Song, H.; Morris, G. Using mesoporous carbon electrodes for brackish water desalination. Water Res. 2008, 42, 2340-2348. [CrossRef] [PubMed]

38. Suganuma, S.; Nakajima, K.; Kitano, M.; Yamaguchi, D.; Kato, H.; Hayashi, S.; Hara, M. Hydrolysis of cellulose by amorphous carbon bearing $\mathrm{SO}_{3} \mathrm{H}, \mathrm{COOH}$, and $\mathrm{OH}$ groups. J. Am. Chem. Soc. 2008, 130, 12787-12793. [CrossRef] [PubMed]

39. Infraed and Ramn Characteristic Group Frequencies. Available online: https://www. researchgate.net/profile/Muzammil_Iqbal2/post/Authentic_IR_spectral_database/attachment/ 59d6591679197b80779aebbd/AS:540994395439105@1505994523971/download/Infrared+and+Raman+ Characteristic+Group+Frequencies+by+George+Socrates.pdf (accessed on 19 April 2018).

40. Barkauskas, J.; Dervinyte, M. Investigation of the functional groups on the surface of activated carbons. J. Serbian Chem. Soc. 2004, 69, 363-375. [CrossRef]

41. Reina, A.; Jia, X.; Ho, J.; Nezich, D.; Son, H.; Bulovic, V.; Dresselhaus, M.S.; Kong, J. Large area, few-layer graphene films on arbitrary substrates by chemical vapor deposition. Nano Lett. 2008, 9, 30-35. [CrossRef] [PubMed]

42. Liu, Y.; Zhao, Y.; Li, K.; Wang, Z.; Tian, P.; Liu, D.; Yang, T.; Wang, J. Activated carbon derived from chitosan as air cathode catalyst for high performance in microbial fuel cells. J. Power Sources 2018, 378, 1-9. [CrossRef]

43. Xu, S.; Yong, L.; Wu, P. One-pot, green, rapid synthesis of flowerlike gold nanoparticles/reduced graphene oxide composite with regenerated silk fibroin as efficient oxygen reduction electrocatalysts. ACS Appl. Mater. Interfaces 2013, 5, 654-662. [CrossRef] [PubMed]

44. Maslova, O.; Ammar, M.; Guimbretière, G.; Rouzaud, J.-N.; Simon, P. Determination of crystallite size in polished graphitized carbon by Raman spectroscopy. Phys. Rev. B 2012, 86. [CrossRef]

45. Matthews, M.; Pimenta, M.; Dresselhaus, G.; Dresselhaus, M.; Endo, M. Origin of dispersive effects of the Raman D band in carbon materials. Phys. Rev. B 1999, 59. [CrossRef]

46. Tai, Z.; Zhang, Q.; Liu, Y.; Liu, H.; Dou, S. Activated carbon from the graphite with increased rate capability for the potassium ion battery. Carbon 2017, 123, 54-61. [CrossRef]

47. Keeping, M.; Reynolds, O. Silicon in agriculture: New insights, new significance and growing application. Ann. Appl. Biol. 2009, 155. [CrossRef]

48. Yang, D.; Velamakanni, A.; Bozoklu, G.; Park, S.; Stoller, M.; Piner, R.D.; Stankovich, S.; Jung, I.; Field, D.A.; Ventrice, C.A. Chemical analysis of graphene oxide films after heat and chemical treatments by $\mathrm{X}$-ray photoelectron and Micro-Raman spectroscopy. Carbon 2009, 47, 145-152. [CrossRef]

49. Seah, M. The quantitative analysis of surfaces by XPS: A review. Surf. Interface Anal. 1980, 2, $222-239$. [CrossRef]

50. Burke, G.M.; Wurster, D.E.; Berg, M.J.; Veng-Pedersen, P.; Schottelius, D.D. Surface characterization of activated charcoal by X-ray photoelectron spectroscopy (XPS): Correlation with phenobarbital adsorption data. Pharm. Res. 1992, 9, 126-130. [CrossRef] [PubMed]

51. Smíšek, M.; Černý, S. Active Carbon: Manufacture, Properties and Applications; Elsevier Publishing Company: New York, NY, USA, 1970; Volume 12.

52. Lillo-Ródenas, M.; Cazorla-Amorós, D.; Linares-Solano, A. Understanding chemical reactions between carbons and $\mathrm{NaOH}$ and $\mathrm{KOH}$ : An insight into the chemical activation mechanism. Carbon 2003, 41, 267-275. [CrossRef]

53. Lillo-Ródenas, M.; Juan-Juan, J.; Cazorla-Amorós, D.; Linares-Solano, A. About reactions occurring during chemical activation with hydroxides. Carbon 2004, 42, 1371-1375. [CrossRef]

54. Viculis, L.M.; Mack, J.J.; Kaner, R.B. A chemical route to carbon nanoscrolls. Science 2003, 299, 1361. [CrossRef] [PubMed]

(C) 2018 by the authors. Licensee MDPI, Basel, Switzerland. This article is an open access article distributed under the terms and conditions of the Creative Commons Attribution (CC BY) license (http://creativecommons.org/licenses/by/4.0/). 